\title{
CENP-E Inhibitor GSK-923295
}

National Cancer Institute

\section{Source}

National Cancer Institute. CENP-E Inhibitor GSK-923295. NCI Thesaurus. Code C91080.

A small-molecule inhibitor of the mitotic kinesin centromere-associated protein E (CENP-

E), with potential antineoplastic activity. Upon administration, GSK-923295 binds to and inhibits CENP-E, thereby preventing cell division, inducing cell cycle arrest, and ultimately leading to an inhibition of cell proliferation. CENP-E, a kinetochore-associated mitotic kinesin, plays an essential role in chromosome movement during mitosis and regulates cell-cycle transition from metaphase to anaphase. 